\title{
Determining the Appropriate Time Series Model for the Malaysia Stock Price during Continuous Pandemic Waves: Case of COVID-19
}

\author{
Nor Alwani Omar, Salina Mad, Ezzah Suraya Sarudin
}

To Link this Article: http://dx.doi.org/10.6007/IJARBSS/v11-i10/11172 DOI:10.6007/IJARBSS/v11-i10/11172

Received: 03 August 2021, Revised: 26 August 2021, Accepted: 20 September 2021

Published Online: 24 October 2021

In-Text Citation: (Omar et al., 2021)

To Cite this Article: Omar, N. A., Mad, S., \& Sarudin, E. S. (2021). Determining the Appropriate Time Series Model for the Malaysia Stock Price during Continuous Pandemic Waves: Case of COVID-19. International Journal of Academic Research in Business and Social Sciences, 11(10), 962 - 974.

Copyright: (c) 2021 The Author(s)

Published by Human Resource Management Academic Research Society (www.hrmars.com) This article is published under the Creative Commons Attribution (CC BY 4.0) license. Anyone may reproduce, distribute, translate and create derivative works of this article (for both commercial and non-commercial purposes), subject to full attribution to the original publication and authors. The full terms of this license may be seen at: http://creativecommons.org/licences/by/4.0/legalcode

Vol. 11, No. 10, 2021, Pg. $962-974$

Full Terms \& Conditions of access and use can be found at http://hrmars.com/index.php/pages/detail/publication-ethics 


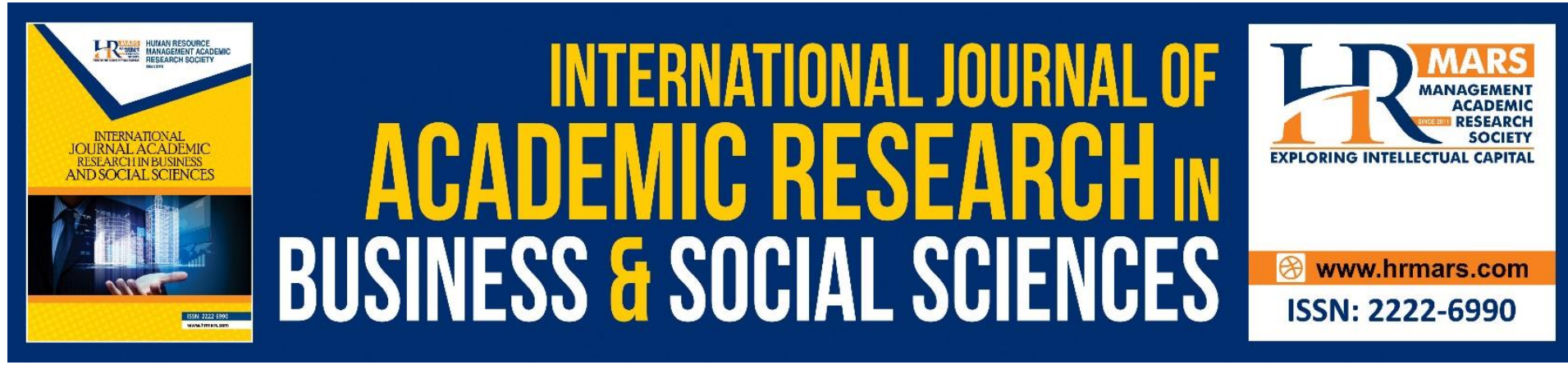

\title{
Determining the Appropriate Time Series Model for the Malaysia Stock Price during Continuous Pandemic Waves: Case of COVID-19
}

\author{
Nor Alwani Omar \\ Faculty of Computer and Mathematical Sciences, Universiti Teknologi MARA, Perak Branch, \\ Tapah Campus, 35400 Tapah Road, Perak, MALAYSIA. \\ Email: noralwani@uitm.edu.my
}

Salina Mad

Faculty of Accountancy, Universiti Teknologi MARA, Perak Branch, Tapah Campus, 35400 Tapah Road, Perak, MALAYSIA.

Email: salina2439@uitm.edu.my

\author{
Ezzah Suraya Sarudin \\ Faculty of Computer and Mathematical Sciences, Universiti Teknologi MARA, Perak Branch, \\ Tapah Campus, 35400 Tapah Road, Perak, MALAYSIA. \\ Email: ezzahsuraya@uitm.edu.my
}

\begin{abstract}
As the series of COVID-19 outbreaks was reported and the declaration of this disease as pandemic, the global financial market, including Malaysia has affected. The uncertainty of this pandemic has led to larger volatility and an appropriate time series model are required to guarantee that the market players made a wise investment decision. Therefore, this study aims to investigate the movement of FTSE Bursa Malaysia stock indices and determine the appropriate model for the sample period. We included the daily data from January 2020 to August 2021 to overview the stock market volatility and Autoregressive Integrated Moving Average (ARIMA) was applied to determine a reliable model. The Generalized Autoregressive Conditional Heteroscedasticity (GARCH) models then was fitting in when the presence of heteroscedasticity in the data set was discovered. The result has shown that $\operatorname{ARIMA}(1,2,1)-$ $\operatorname{GARCH}(1,1)$ is the fitted model and the volatility was well-determined during the pandemic. In addition, the existence of leverage effect was confirmed using Exponential GARCH (EGARCH) and a positive risk premium was detected using Symmetric Mean GARCH (GARCH$M)$. Finally, it is recommended for researchers to use an extended sample period to see the behaviour of the stock market when Malaysia vaccination program has completed.
\end{abstract}

Keywords: Volatility, ARIMA-GARCH, COVID-19, Pandemic, Stock Market 


\section{Introduction}

The Coronavirus (COVID-19) outbreak was later announced as a pandemic has negatively hit the financial market as most countries started implementing the movement restriction and closure of business activities (Toda, 2020). Baldwin and Mauro (2020) stated that the economic system was undergoing a few blows, which are the reduction in household spending, disruption in the import and export activities, and lastly, the "wait-and-see" approach will affect the manufacturing sector. Meanwhile, Ozili (2020) highlighted that the COVID-19 pandemic had disrupted the stock market by shutting down the business and corporate activities. Besides, the study also mentioned that the uncertainty of this pandemic has led to larger volatility in the stock market, and it influenced the investors' investment decisions in the stock market.

When China decided to implement a lockdown to control the widespread of the disease, this has affected the supply and demand throughout the world and negatively impacted Malaysia's economic system. In addition, the pandemic has significantly impacted Malaysia's financial markets, especially with the implementation of travel restrictions, social distancing, lockdowns and massive unemployment that have struck economies for almost two years. In Malaysia, the first COVID-19 cases were recorded on 25 January 2020 and increased dramatically to 2626 cases in 2 months. Due to the outbreak, the government of Malaysia has announced a series of movement control orders (MCO) from March 2020 till the present. That had increased the volatility of the stock market; thus, modelling them is essential. Shehzad et al. (2020) show that the Asian market was less affected by COVID-19 than the European market.

In contrast, Zeren and Hizarci (2020) found a cointegration relationship in the stock markets in China, Korea, and Spain. However, they observed no connection between the COVID cases and the performance of the stock markets in France, Germany, and Italy, hence signalling that these stock markets were not affected by the spread of COVID-19. In the context of the Malaysian market, Lee et.al (2020) found that the numbers of COVID-19 cases tended to adversely affect the performance of the $\mathrm{KLCl}$ index and all sectoral indices, except for the Real Estate Investment Fund (REIT) index.

Previously, many researchers used the ARIMA-GARCH model in modelling the stock market during financial crises (Shamiri and Isa, 2009; Ahmed and Suliman, 2011; Islam, 2013). The Autoregressive Integrated Moving Average (ARIMA) are simplistic linear models but cannot find complex, subtle patterns in the time-series data; meanwhile, the Generalised Autoregressive Conditional Heteroscedasticity (GARCH) is a model that is widely used in measuring the volatility of high-frequency financial data like daily stock or stock index returns. Chaudhary et al (2020) analysed the stock market indices of the top 10 countries based on GDP using the standard GARCH model. That result found that the pandemic has increased the volatility of these indices. Shehzad et al (2020) also applied the Asymmetric Power GARCH model with dummy variables to investigate the impact of the Global Financial Crisis and COVID-19 on some of the stock markets indices such as S\&P 500 (US), Nasdaq Composite Index (US), DAX 30 (Germany), FTSE MIB (Italy), Nikkei 225 Index (Japan), and SSEC (China).

In addition, a study by Chuan et. al (2021) found that EGARCH can detect the leverage effect when stock market returns are negatively correlated to its volatility. They also documented 
that standard GARCH(1,1), GARCH-M(1,1), and $\operatorname{EGARCH}(1,1)$ models are suitable to predict volatility for both Malaysia and Singapore stock market returns. This result aligned with Mohd Nor \& Shamiri (2007) research that discovered the asymmetric models, such as EGARCH and GJR-GARCH, outperform the symmetric GARCH model in the Malaysian and Singaporean stock markets. Goudarzi and Ramanarayanan (2011) also used asymmetric models of EGARCH and TGARCH to study the effects of good news and bad news on volatility in the Indian stock market. In addition, Alagidede and Panagiotidis (2009) also used GARCH models to examine the relationship between volatility and risk premium on the largest 7-African stock markets.

The stock market is an essential part of the capital market. Estimating financial time series such as stock returns is vital for investors, financial analysts, and policymakers. As Abdalla \& Suliman (2012) mentioned, the time series model guarantees that the market players made a wise investment decision. Besides that, data from the time series of the stock market also plays an essential role in the financial market as the information gained from the analysis would determine the profits earned. For that reason, the volatility of the stock market is considered a widespread measure of risk for investors and modelling the volatility became crucial to ensure the investor does not miss a good investment opportunity. Accordingly, volatility plays a vital role in the financial market, but it is not directly observable, varies over time and is highly sensitive to financial market changes (Awalludin et. al., 2018). One of the significant drawbacks of the previous study, none of them has included all four waves of the outbreak in Malaysia, especially the recent two waves that hit the healthcare system. Therefore, like Lee et. al (2020) recommended, this paper analysed a more extended sample period that considered all the waves that had hit Malaysia so far and developed a fitted and reliable ARIMA-GARCH model to find out what is happening in Malaysia stock market.

\section{Data and Methodology}

This paper considers the four waves of the outbreak in Malaysia and uses FTSE Bursa Malaysia stock price from January 2020 until August 2021. We downloaded the daily time series from Yahoo Finance as per a study by Omar and Halim (2015) and Chuan et. al (2021). Then, the daily return was calculated using the natural log difference approach (Duttilo et. al, 2021). Besides, to emphasize the COVID-19 pandemic outbreaks, the considered period does not include the financial crises (1997 and 2008) and the political issues in 2019.

The investigation was performed using the five-step procedures: data collection, trend analysis, differencing, model identification, and model evaluation. The models used in this study was concisely chosen based on past researches. The reliability of these models in capturing the dynamic characteristics of stock index returns was successfully demonstrated by many researchers (Gherghina et al., 2021; Duttilo et al., 2021). Floros (2008) also models the volatility of middle-east stock indices using GARCH-type models over the two financial crises, the Asian Financial Crisis and Global Financial Crisis, and concluded that the GARCH models are proficient in capturing the dynamics of stock returns like volatility clustering and leverage effects.

\section{Autoregressive Moving-Average (ARMA)}

Box and Jenkins has designed the ARMA model as a random time-sequence model. This model consist of three basic types of ARMA model, which are Autoregressive (AR) model, Moving Average (MA) model, and the Autoregressive Moving Average (ARMA). The equation of the ARMA model is written below. 


$$
Y_{t}-\varphi_{1} Y_{t-1}-\ldots-\varphi_{p} Y_{t-p}=\alpha_{t}-\theta_{1} \alpha_{t-1}-\ldots-\theta_{q} \alpha_{t-q}
$$

\section{Generalized Autoregressive Conditional Heteroscedasticity (GARCH)}

A general observation about the unexpected component of asset returns is that large shocks tend to be followed by more significant shocks, and small shocks tend to be followed by more small changes in either direction. In other words, the volatility of asset returns appears to be serially correlated. The econometric term describes this feature as the autoregressive conditional heteroscedasticity $(\mathrm{ARCH})$, which states that the time-series variance depends on their past realizations. The standard ARCH model was introduced by Engle (1982) and generalized (GARCH) by Engle and Bollerslev (1986). In his model, Engle defines conditional variance as a deterministic function of lagged squared residuals. In the ARCH ( $p$ ) model, the conditional variance is given by:

$$
\sigma_{\mathrm{t}}^{2}=\omega+\alpha \epsilon_{\mathrm{t}-1}^{2}
$$

Where $\omega$ and $\alpha$ non-negative constants (in order for $\sigma_{t}^{2}$ to be non-negative).

The equation above gives the ARCH model formulation to depict volatility as the clustering of large shocks to the dependent variable. This formula then was extended by Bollerslev and introducing lagged conditional variances in the conditional variance equation. The GARCH model is commonly used in its most simple form, where the simplest $\operatorname{GARCH}(1,1)$ specification is:

$\sigma_{\mathrm{t}}^{2}=\omega+\alpha \epsilon_{\mathrm{t}-1}^{2}+\beta \sigma_{\mathrm{t}-1}^{2}$

Where $\omega$ is a constant

$\epsilon_{\mathrm{t}-1}^{2}$ is the $\mathrm{ARCH}$ term

$\sigma_{\mathrm{t}-1}^{2}$ is the GARCH term

Higher-order GARCH models denoted GARCH (q,p) can be estimated by choosing either $q$ or $p$ greater than 1 . The representation of the $\operatorname{GARCH}(q, p)$ variance is:

$$
\sigma_{\mathrm{t}}^{2}=\omega+\sum_{\mathrm{j}=1}^{\mathrm{q}} \beta_{\mathrm{j}} \sigma_{\mathrm{t}-\mathrm{j}}^{2}+\sum_{\mathrm{i}=1}^{\mathrm{p}} \alpha_{\mathrm{i}} \in_{\mathrm{t}-1}^{2}
$$

Exponential Generalized Autoregressive Conditional Heteroscedasticity (EGARCH)

EGARCH is used to model excess conditional kurtosis in stock return indices based on a generalized exponential distribution (Nelson, 1991). The extension by Nelson consider that the down movements are more significant in estimating the volatility. Therefore, the specification for the conditional variance of the EGARCH model is as following:

$$
\log \left(\sigma_{t}^{2}\right)=\omega+\sum_{j=1}^{q} \beta_{j} \log \left(\sigma_{t-j}^{2}\right)+\sum_{i=1}^{p} \alpha_{i}\left|\frac{\epsilon_{t-i}}{\sigma_{t-i}}\right|+\sum_{k=1}^{r} \gamma_{k} \frac{\epsilon_{t-k}}{\sigma_{t-k}}
$$

The left-hand side is the $\log$ of the conditional variance. This implies that the leverage effect is exponential rather than quadratic and that forecasts of the conditional variance are guaranteed to be nonnegative. The presence of leverage effects can be tested by the hypothesis that $\gamma_{i}<0$. The impact is asymmetric if $\gamma_{i} \neq 0$. 


\section{Symmetric Mean Generalized Autoregressive Conditional Heteroscedasticity (GARCH-M)}

Engle et al. (1987) developed the symmetric mean GARCH (GARCH-M) model in the following equations:

$$
\begin{gathered}
\gamma_{t}=c+\lambda \sigma_{t}^{2}+u_{t} \\
\sigma_{t}^{2}=\alpha+\theta_{1} \sigma_{t-1}^{2}+b_{1} u_{t-1}^{2}
\end{gathered}
$$

The mean equation includes the variance $\left(\sigma_{t}^{2}\right)$ because the variance serves as a proxy for risk. Investors are risk-averse, and the parameter $\lambda$ reflects the risk premium. Consequently, investors are willing to increase their holdings in a risky asset if they earn a risk premium for doing so. The residual has the same relationship to the random noise or $\varepsilon_{t}=\sigma_{t} z_{t}$.

\section{Results and Discussions}

\section{Trend Analysis}

The graph in Figure 1 shows that the stock price presented several deterministic trends throughout the four waves of outbreak from the sample period of January 2020 till August 2021. The first outbreak started on 22 January 2020, has led to the decline of FTSE Bursa Malaysia stock price and later noted a dramatic drop after the second wave of the outbreak on 28 February 2020 (Hashim et al., 2021). The sharp decline was induced by the government's announcement of the first Movement Control Order (MCO) on 18 March 2020. For instance, Goudarzi and Ramanarayanan (2011) find that negative news has a more significant impact on volatility than positive news. After successfully lowering the number of Covid-19 cases between single- and double-digit, Malaysia hit the third wave of the outbreak in early October 2020 due to an election in one of the states in the country. The fourth epidemic wave hit Malaysia on June 2021, although Malaysia is still recovering from the third wave. This series of outbreaks has badly affected the country's healthcare system and caused a continuous drop in the stock price till August 2021. Therefore, by analysing the graph, the sample data is obviously non-stationary.

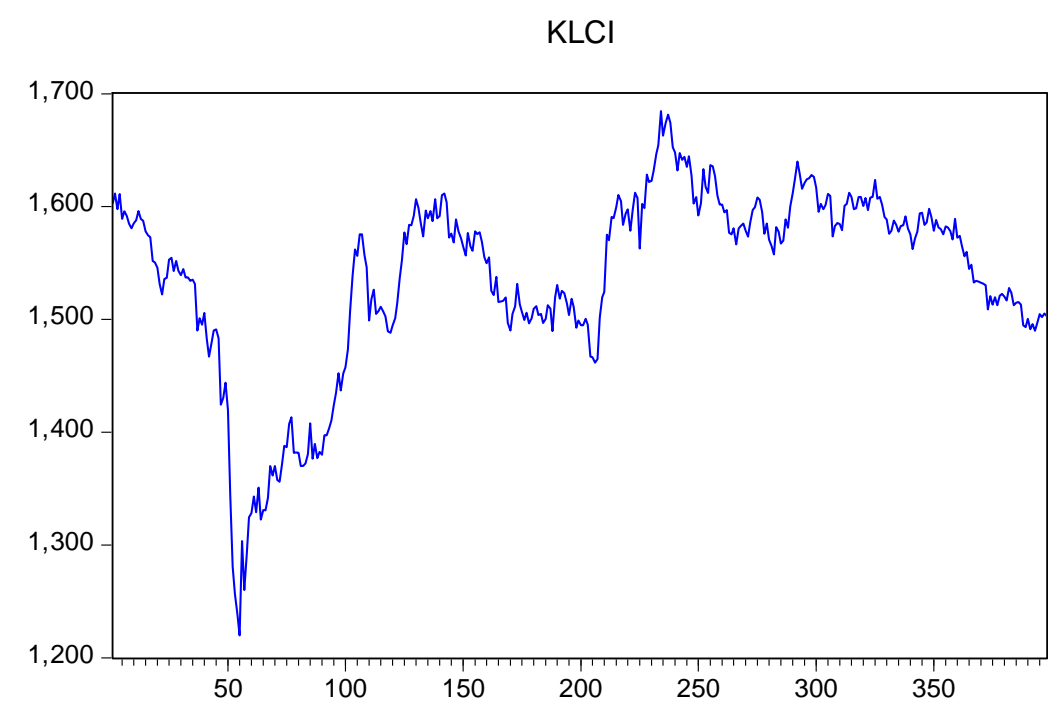

Figure 1: Time Series Plot for FTSE Bursa Malaysia KLCl from January 2020 till August 2021 
INTERNATIONAL JOURNAL OF ACADEMIC RESEARCH IN BUSINESS AND SOCIAL SCIENCES Vol. 11, No. 10, 2021, E-ISSN: 2222-6990 @ 2021 HRMARS

\begin{tabular}{|c|c|c|c|c|c|c|c|c|}
\hline & \multicolumn{8}{|c|}{ Correlogram of $\mathrm{KLCl}$} \\
\hline \multicolumn{9}{|c|}{$\begin{array}{l}\text { Date: } 08 / 18 / 21 \text { Time: } 13: 27 \\
\text { Sample: } 1398 \\
\text { Included observations: } 398\end{array}$} \\
\hline \multicolumn{2}{|c|}{ Autocorrelation } & \multicolumn{2}{|c|}{ Partial Correlation } & & $\mathrm{AC}$ & PAC & Q-Stat & Prob \\
\hline 1 & & । & & 1 & 0.981 & 0.981 & 386.29 & 0.000 \\
\hline 1 & & & י & 2 & 0.964 & 0.026 & 760.06 & 0.000 \\
\hline 1 & E & & 1 & 3 & 0.944 & -0.089 & 1119.2 & 0.000 \\
\hline 1 & 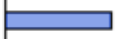 & & 1 & 4 & 0.921 & -0.079 & 1462.3 & 0.000 \\
\hline 1 & $\square$ & & 1 & 5 & 0.898 & -0.032 & 1789.1 & 0.000 \\
\hline 1 & 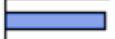 & & 1 & 6 & 0.874 & -0.022 & 2099.4 & 0.000 \\
\hline 1 & $\square$ & 1 & 1 & 7 & 0.851 & 0.005 & 2393.9 & 0.000 \\
\hline 1 & $\square$ & & ין & 8 & 0.828 & 0.026 & 2673.8 & 0.000 \\
\hline 1 & & । & 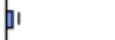 & 9 & 0.808 & 0.055 & 2941.0 & 0.000 \\
\hline I & $\square$ & & $\int_{1}$ & 10 & 0.789 & 0.022 & 3196.5 & 0.000 \\
\hline 1 & 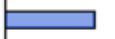 & & 1 & 11 & 0.768 & -0.079 & 3439.3 & 0.000 \\
\hline 1 & 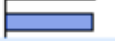 & & 1 & 12 & 0.749 & 0.008 & 3670.5 & 0.000 \\
\hline
\end{tabular}

Figure 2: ACF and PACF of FTSE Bursa Malaysia KLCI

Referring to the movement displayed in the graph, Figure 2 shows that the ACF tails off extremely slowly over the lags. This result was supporting the early hypothesis that the data is non-stationary. Then, differencing was performed and we find that the stationary data only acquired after the second differencing.

DKLCl2

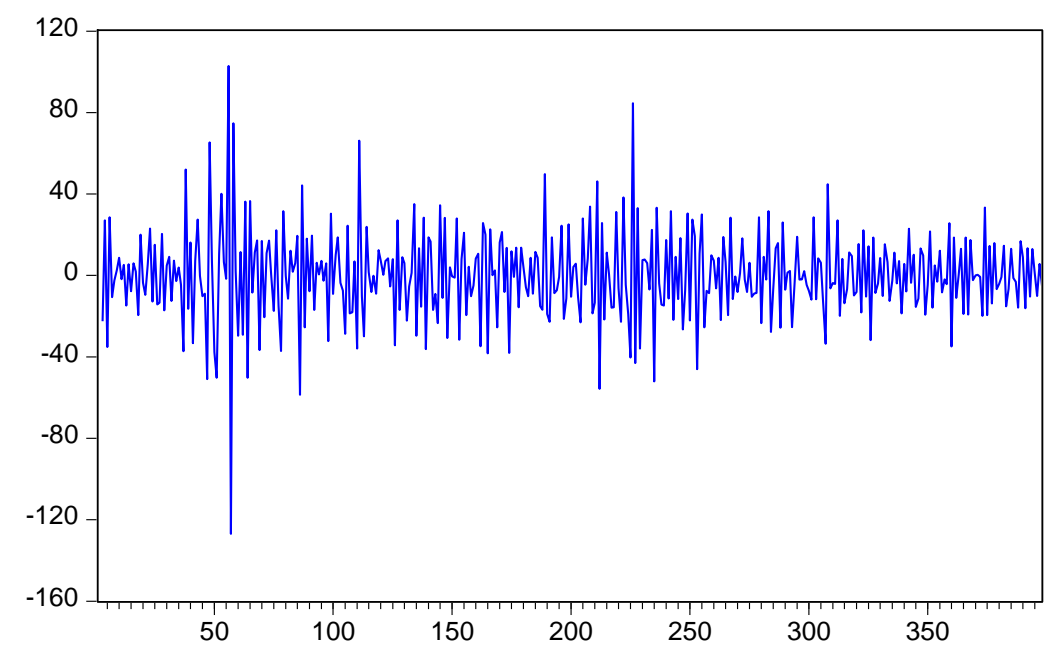

Figure 3: Time Series Plot of FTSE Bursa Malaysia $\mathrm{KLCl}$ after second differencing 


\begin{tabular}{|c|c|c|c|c|c|c|}
\hline \multicolumn{7}{|c|}{ Correlogram of DKLCI2 } \\
\hline \multicolumn{7}{|c|}{$\begin{array}{l}\text { Date: } 08 / 18 / 21 \text { Time: } 13: 56 \\
\text { Sample: } 1398 \\
\text { Included observations: } 396\end{array}$} \\
\hline Autocorrelation & Partial Correlation & & $A C$ & PAC & Q-Stat & Prob \\
\hline$\square$, & $\square$, & 1 & -0.564 & -0.564 & 127.05 & 0.000 \\
\hline וp' & $\square 1$ & 2 & 0.081 & -0.348 & 129.71 & 0.000 \\
\hline 11 & $\square 1$ & 3 & -0.005 & -0.233 & 129.72 & 0.000 \\
\hline 11 & 며 & 4 & -0.000 & -0.165 & 129.72 & 0.000 \\
\hline 11 & 니 & 5 & -0.002 & -0.125 & 129.72 & 0.000 \\
\hline 11 & C. & 6 & 0.003 & -0.092 & 129.73 & 0.000 \\
\hline 11 & 1 & 7 & 0.002 & -0.062 & 129.73 & 0.000 \\
\hline 111 & di & 8 & -0.023 & -0.083 & 129.94 & 0.000 \\
\hline id 1 & 미 & 9 & -0.038 & -0.176 & 130.53 & 0.000 \\
\hline $1 \mathrm{p}$ & 1 & 10 & 0.093 & -0.076 & 134.05 & 0.000 \\
\hline 1 & d & 11 & -0.067 & -0.084 & 135.87 & 0.000 \\
\hline וpl & 101 & 12 & 0.030 & -0.063 & 136.24 & 0.000 \\
\hline
\end{tabular}

Figure 4: ACF and PACF of FTSE Bursa Malaysia KLCl after Second Differencing

From Figure 3, it shown that the stock price data fluctuated in different degree indicating that volatility changes over time, especially during the second and third waves of the outbreak when there is a remarkable high spike presented. An Islamic missionary and election caused these fluctuations, indicating that the data that include all four waves of outbreak is stationary in mean. Therefore, we assumed heteroscedasticity was exist in the sample period. This study also analyzes the ACF and PACF graphs as additional evidence before proceed with the heteroscedasticity test. Figure 4 clearly shows that there exist many significant values at the short lags. For that reason, ACF and PACF are not suitable in determining the fitted model to this sample data. Hence, this paper consider the theory of parsimony that focus on simplest model to ensure an accurate and reliable model can be derived.

\section{Model Identification}

By starting the model identification using the simplest model, we firstly generated and reported the output of models AR (1), MA (1) and ARMA $(1,1)$ in Table 1 . The result presented that MA (1) coefficient was significant at a 5\% significance level and fitted to the model. Additionally, the coefficient falls within -1 and 1 , indicating that it fulfils the stationarity and invertibility conditions for the model. Besides that, MA (1) was considered as a better model since the value of R-square (0.519031) is higher than those in the AR (1) model (0.319297). This value indicate the reliability of this model in handling the variation of stock price compared to the later model. The Ljung-Box test also was done to verify the distribution of the residuals, whether it is independent or not. This independent residual shows that the main assumptions for the white noise was fulfil. The reported analysis shows that the white noise assumption was fulfilled at a few but not at the subsequent short lag. Thus, the MA (1) model does not satisfy the white noise assumption; hence a better model is needed. In addition, the patterns displayed by both ACF and PACF show significant values, supporting the fact that autocorrelation exists among the residuals. For that reason, a higher model is predicted to fit the stock price as there is a significant value around lag 3 for both ACF and PACF graphs. Deriving of a new ARMA model is then conducted to the MA (1) model to derived a more suitable model. 
Table 1: Summary Table of the New Derived Models

\begin{tabular}{lllll}
\hline Model & Coefficient & White Noise & AIC & SC \\
\hline AR(1) & OK & NO & 8.657805 & 8.667878 \\
ARMA $(1,1)$ & NO & NO & - & - \\
MA(1) & OK & OK & 8.310539 & 8.320594 \\
$M A(2)$ & NO & NO & - & - \\
MA(3) & NO & NO & - & - \\
ARMA $(2,1)$ & NO & NO & - & - \\
ARMA $(1,2)$ & OK & OK & 8.311159 & 8.341378 \\
ARMA $(2,2)$ & NO & NO & - & - \\
ARMA $(1,3)$ & NO & NO & - & - \\
\hline
\end{tabular}

By reviewing the above table, we discovered that ARMA $(1,2)$ fits the data satisfactorily as the coefficient of AR and MA are significant and fulfilled the white noise assumptions. Thus, this statement was aligned with the previous assumption that a model with higher-order is required. Besides, the value of Akaike info Criterion (AIC) is lower in MA (1), making it a better model. Then, Overfitting is conducted again to get MA $(3), \operatorname{ARMA}(1,3)$ and $\operatorname{ARMA}(2,2)$ to verify the suitability of the predicted model. However, the result from Overfitting shows that all three models are not fitted for this sample period. After that, the ARCH-LM test is conducted to assess heteroscedasticity among the variance of the observed sample data. Based on the output in Table 2, it was evident that the null hypothesis is rejected due to the significant $p$-value at the $5 \%$ level, implying that heteroscedasticity exists within the data set. Hence, the Generalized Autoregressive Conditional Heteroscedasticity (GARCH) shall be used to model volatility in the stock prices.

Table 2: ARCH-LM Test

\begin{tabular}{|c|c|c|}
\hline \multicolumn{3}{|c|}{ Heteroskedasticity Test: ARCH } \\
\hline F-statistic & 9.531443 & Prob. $F(12,371)$ \\
\hline Obs*R-squared & 90.48814 & Prob. Chi-Square(12) 0.0000 \\
\hline
\end{tabular}

\section{Model Evaluation}

As expected, the output of $\operatorname{ARIMA}(0,2,1)-\operatorname{GARCH}(1,1)$ presented that the coefficient is significant, hence accepting that $\operatorname{ARIMA}(0,2,1)$ is a reliable model. However, it was recommended to fit $\operatorname{GARCH}(1,1)$ with a higher order model and find a fitted model. The result from the overfitting was presented in Table 3.

Table 3: Summary Table of the New Derived Models by Overfitting for ARIMA-GARCH

\begin{tabular}{lllll}
\hline Model & Coefficient & White Noise & AIC & SC \\
\hline MA(1) & OK & NO & 8.163253 & 8.203469 \\
MA(2) & NO & NO & - & - \\
$\operatorname{ARMA}(1,1)$ & OK & OK & 8.149151 & 8.199517 \\
$\operatorname{ARMA}(2,1)$ & NO & - & - & - \\
$\operatorname{ARMA}(1,2)$ & OK & NO & - & - \\
$\operatorname{ARMA}(2,2)$ & NO & - & - & - \\
$\operatorname{ARMA}(1,3)$ & OK & OK & 8.174635 & 8.245146 \\
\hline
\end{tabular}


After conducting several overfitting, the final model obtained was ARIMA $(1,2,1)-$ GARCH $(1,1)$. It was showing that both ARMA $(1,1)$ and ARMA $(1,3)$ are significant, but using the value of AIC in comparison, it was supported that ARMA $(1,1)$ is a better model since it has lower value of AIC. The output of the constructed model is as shown in Table 4.

Table 4: ARIMA $(1,2,1)-$ GARCH $(1,1)$

\begin{tabular}{lllll}
\hline Variable & Coefficient & Std. Error & z-Statistic & Prob. \\
\hline AR(1) & -0.116328 & 0.057792 & -2.012886 & 0.0441 \\
MA(1) & -0.998854 & 0.001530 & -652.9998 & 0.0000 \\
\hline \multicolumn{5}{l}{ Variance Equation } \\
\hline C & 9.168433 & 4.719203 & 1.942793 & 0.0520 \\
RESID(-1)^2 & 0.093224 & 0.022470 & 4.148753 & 0.0000 \\
GARCH(-1) & 0.866427 & 0.041342 & 20.95771 & 0.0000 \\
R-squared & 0.516312 & Mean dependent var & 0.028886 \\
Adjusted R-squared & 0.515081 & S.D. dependent var & 22.22048 \\
S.E. of regression & 15.47349 & Akaike info criterion & 8.149151 \\
Sum squared resid & 94095.52 & Schwarz criterion & 8.199517 \\
Log likelihood & -1604.457 & Hannan-Quinn criter. & 8.169106 \\
Durbin-Watson stat & 1.819183 & & & \\
\hline
\end{tabular}

Referring to the reported output, it shows that both coefficient are significant at $5 \%$ level and fulfill the stationarity and invertibility conditions respectively. Because of that, the GARCH $(1,1)$ model are suitable in modelling the time-varying conditional variance that exist in the data set.

Table 5: ARIMA $(0,2,1)$ - EGARCH $(1,1)$

\begin{tabular}{lllll}
\hline Variable & Coefficient & Std. Error & z-Statistic & Prob. \\
\hline $\mathrm{MA}(1)$ & -0.998879 & 0.001200 & -832.3981 & 0.0000 \\
\hline Variance Equation & & & & \\
\hline $\mathrm{C}(2)$ & 0.062630 & 0.119280 & 0.525068 & 0.5995 \\
$\mathrm{C}(3)$ & 0.192959 & 0.041378 & 4.663333 & 0.0000 \\
$\mathrm{C}(4)$ & -0.047091 & 0.021278 & -2.213085 & 0.0269 \\
$\mathrm{C}(5)$ & 0.960993 & 0.026741 & 35.93660 & 0.0000 \\
$\mathrm{R}-$ squared & 0.517980 & Mean dependent var & -0.028005 \\
Adjusted R-squared & 0.517980 & S.D. dependent var & 22.22120 \\
S.E. of regression & 15.42766 & Akaike info criterion & 8.169210 \\
Sum squared resid & 94015.07 & Schwarz criterion & 8.219480 \\
Log likelihood & -1612.504 & Hannan-Quinn criter. 8.189125 \\
Durbin-Watson stat & 2.071543 & \multicolumn{3}{c}{} \\
\hline
\end{tabular}


Table 6: ARIMA $(0,2,1)-$ GARCH-M $(1,1)$

\begin{tabular}{lllll}
\hline Variable & Coefficient & Std. Error & z-Statistic & Prob. \\
\hline @SQRT(GARCH) & $2.21 \mathrm{E}-05$ & 0.000254 & 0.087076 & 0.9306 \\
$\mathrm{MA}(1)$ & -0.998357 & 0.001545 & -646.3211 & 0.0000 \\
\hline \multicolumn{5}{l}{ Variance Equation } \\
\hline $\mathrm{C}$ & 9.137047 & 5.070829 & 1.801884 & 0.0716 \\
RESID(-1)^2 & 0.090570 & 0.023532 & 3.848777 & 0.0001 \\
GARCH(-1) & 0.868903 & 0.043710 & 19.87881 & 0.0000 \\
R-squared & 0.518619 & Mean dependent var & -0.028005 \\
Adjusted R-squared & 0.517397 & S.D. dependent var & 22.22120 \\
S.E. of regression & 15.43698 & Akaike info criterion & 8.159428 \\
Sum squared resid & 93890.30 & Schwarz criterion & 8.209699 \\
Log likelihood & -1610.567 & Hannan-Quinn criter. & 8.179344 \\
Durbin-Watson stat & 2.075378 & & & \\
\hline
\end{tabular}

Then, the model is fitted with an EGARCH and GARCH-M, and after conducted overfit and underfit, the study finds that MA(1) is the best model for both of them. Therefore, ARIMA $(0,2,1)-\operatorname{EGARCH}(1,1)$ and ARIMA $(0,2,1)-$ GARCH-M $(1,1)$ are the fitted model for EGARCH and GARCH-M. EGARCH was used to identify the leverage effect among the stock prices during the waves of COVID-19 outbreak. In contrast, GARCH-M is used to investigate the proposition under Capital Asset Pricing Model (CAPM). From the output shown in Table 5, C (4) coefficient is negative and significant under a $5 \%$ significant level. This result suggested that the bad news will give a big blow to the fluctuations of the stock prices compared to the good news (Goudarzi and Ramanarayanan, 2011). It was proven by the presence of downward trend for the past two years and the unconsistent functuations in the initial analysis presented in Figure 1. Instead of that, the result of GARCH-M indicate the risk premium is not significant to hedge against holding a risky asset. Or the asset in question may not be risky to hold.

\section{Conclusions and Recommendations}

The risk is usually uncertain for the investor, and the huge up and downshifts in both developed and emerging markets are regular in the financial market. Financial crises over the years are a known factor that affects the fluctuations in the stock market. In fighting the spread of COVID-19 for the past two years, the Malaysian stock market has faced an enormous challenge in keeping its volatility. Star Media (2020) reported major shareholders of listed companies has disposed of their shares in the first few trading days of MCO due to the uncertainty caused by the COVID-19 and MCO. Therefore, this research implemented the ARIMA-GARCH model for a daily data set from January 2020 till August 2021 to study stock price movement during four waves of COVID-19 in Malaysia.

This paper finds a deterministic trend in the stock price as the country is fighting with the pandemic. Closure of business activity, movement control order, and struggling to control the widespread disease have led to a dramatic drop in the stock price, as reported by Lee et.al (2020). The analysis on the daily data set showed heteroscedasticity, which led to the use of Generalized Autoregressive Conditional Heteroscedasticity (GARCH) following Alagidede and Panagiotidis (2009). When analyzing the sample period, it also reported that the reliability of the model was change when fitted into GARCH family models. Overfit and underfit were 
conducted to find the best-fitted model for the GARCH, EGARCH and GARCH-M. Finally, we found that ARIMA $(1,2,1)-\operatorname{GARCH}(1,1)$ is the best model for this data set. Besides, the result also shows that the continuous waves of the COVID-19 outbreak have affected the stock market volatility, and the risk premium was positive, indicating the asset maybe not be risky to hold (Chuan et. al, 2021).

This study contributes to the research literature on how the COVID-19 pandemic has affected stock markets' volatility. It shows that the pandemic has changed the characteristics of the GARCH process and its underlying distribution. For further research, it is recommended for researchers to use a more extended sample period to see the behaviour of the stock market after the Malaysia vaccination program has reached herd immunity. In addition, the pre and post-pandemic situation also can be evaluated in the future.

\section{References}

Abdalla, S. Z. S., \& Suliman, Z. (2012). Modelling stock returns volatility: Empirical evidence from Saudi Stock Exchange. International Research Journal of Finance and Economics, 85, 166-179.

Ahmed, A. E. M., \& Suliman, S. Z. (2011). Modeling stock market volatility using GARCH models evidence from Sudan. International journal of business and social science, 2(23).

Alagidede, P., \& Panagiotidis, T. (2009). Modelling stock returns in Africa's emerging equity markets. International review of financial analysis, 18(1-2), 1-11.

Awalludin, S. A., Ulfah, S., \& Soro, S. (2018). Modeling the stock price returns volatility using $\operatorname{GARCH}(1,1)$ in some Indonesia stock prices. In Journal of Physics: Conference Series (Vol. 948, No. 1, p. 012068). IOP Publishing.

Baldwin, R., \& Mauro, B. W. (2020). Economics in the time of COVID-19: A new eBook. VOX CEPR Policy Portal, 2-3.

Chaudhary, R., Bakhshi, P., \& Gupta, H. (2020). Volatility in international stock markets: an empirical study during Covid-19. Journal of Risk and Financial Management, 13(9), 208.

Chuan, J. N., Mahdi, S., \& Kenneth, R. (2021). The Impact of Covid-19 Pandemic on Stock Market Return Volatility: Evidence from Malaysia and Singapore. Asian Economic and Financial Review, 11(3), 191-204.

Duttilo, P., Gattone, S. A., \& Di Battista, T. (2021). Volatility Modeling: An Overview of Equity Markets in the Euro Area during COVID-19 Pandemic. Mathematics, 9(11), 1212.

Engle, R. F. (1982). Autoregressive conditional heteroscedasticity with estimates of the variance of United Kingdom inflation. Econometrica: Journal of the econometric society, 987-1007.

Engle, R. F., \& Bollerslev, T. (1986). Modelling the persistence of conditional variances. Econometric reviews, 5(1), 1-50.

Engle, R. F., Lilien, D. M., \& Robins, R. P. (1987). Estimating time varying risk premia in the term structure: The ARCH-M Model. Econometrica: Journal of the Econometric Society, 55(2), 391-407.

Floros, C. (2008). Modelling volatility using GARCH models: evidence from Egypt and Israel. Middle Eastern Finance and Economics, (2), 31-41.

Gherghina, Ș. C., Armeanu, D. Ș., \& Joldeș, C. C. (2021). COVID-19 Pandemic and Romanian Stock Market Volatility: A GARCH Approach. Journal of Risk and Financial Management, 14(8), 341. 
Goudarzi, H., \& Ramanarayanan, C. S. (2011). Modeling asymmetric volatility in the Indian stock market. International Journal of Business and Management, 6(3), 221.

Hashim, J. H., Adman, M. A., Hashim, Z., Radi, M. F. M., \& Kwan, S. C. (2021). COVID-19 Epidemic in Malaysia: Epidemic Progression, Challenges, and Response. Frontiers in Public Health, 9.

Islam, M. A. (2013). Modeling univariate volatility of stock returns using stochastic GARCH models: Evidence from 4-Asian markets. Australian Journal of Basic and Applied Sciences, 7(11), 294-303.

Lee, K. Y. M., Jais, M., \& Chan, C. W. (2020). Impact of covid-19: evidence from Malaysian stock market. International Journal of Business and Society, 21(2), 607-628.

Nor, M. A. H. S., \& Shamiri, A. (2007). Modeling and forecasting volatility of the Malaysian and the Singporean stock indices using asymmetric GARCH models and non-normal densities. Malaysian Journal of Mathematical Sciences, 1(1), 83-102.

Nelson, D. B. (1991). Conditional heteroskedasticity in asset returns: A new approach. Econometrica: Journal of the Econometric Society, 347-370.

Ozili, P. K. (2020). Covid-19 pandemic and economic crisis: The Nigerian experience and structural causes. Journal of Economic and Administrative Sciences.

Shamiri, A., \& Isa, Z. (2009). Modeling and forecasting volatility of the Malaysian stock markets. Journal of Mathematics and Statistics, 5(3), 234.

Shehzad, K., Xiaoxing, L., \& Kazouz, H. (2020). COVID-19's disasters are perilous than Global Financial Crisis: A rumor or fact?. Finance Research Letters, 36, 101669.

Star Media. (2020). Short position: Cluesless on MCO impact. Retrieved from https://www.thestar.com.my/business/business-news/2020/03/21/short-positionclueless-on-mco-impact

Toda, A. A. (2020). Susceptible-infected-recovered (sir) dynamics of covid-19 and economic impact. arXiv preprint arXiv:2003.11221.

Zeren, F., \& HIZARCI, A. (2020). The impact of COVID-19 coronavirus on stock markets: evidence from selected countries. Muhasebe ve Finans incelemeleri Dergisi, 3(1), 78-84. 